\title{
A Thick Translation of Hmong Oral Epics from the Perspective of Cultural Anthropology
}

DOI: https://doi.org/10.47175/rissj.v3i1.392

\author{
| Fei Wu | \\ Hunan Institute of Engineering, \\ Hunan Province, China \\ 675836543@qq.com
}

\begin{abstract}
Hmong Oral Epics is an oral classic of the Miao people, carrying the cultural memory of the ancient history of the Miao people. The Hmong Oral Epics translated by American sinologist Mark Bender has been praised as "a classic version of transnational cooperation" by scholars. The success of this translation depends on what the translators used flexibly thick translation strategies from the perspective of cultural anthropology, thus making it a good example of the successful application of thick translation to translating national classics. This paper first expounds the theory and feasibility of thick translation of cultural classics from the perspective of cultural anthropology, and then reveals the secret of the success of Mark Bender's translation of Hmong Oral Epics from three aspects, namely the English translation process of Hmong Oral Epics, ethnography orientation, and the translators' comprehensive use of various forms of thick translation both inside and outside translation, with an attempt to promote more Chinese ethnic minority cultural classics to better go to the world. KEYWORDS

Hmong Oral Epics; Translation of Ethnic Classics; thick translation.
\end{abstract}

\section{INTRODUCTION}

Since the 21st century, in response to the "Going out initiative of Chinese Culture", the significant achievements have been made in the study of English translation of Chinese ethnic minority culture and the study on the translation of ethnic classics is an important part of it. The Miao is a cross-border ethnic group, whose culture is one of the most representative cultures of minority ethnic in China. It is of great significance to translate and introduce it, especially to the translation of classics such as Hmong Oral Epics.

Hmong Oral Epics is the essence of the Miao culture. Hmong Oral Epics, also known as "Miao Ancient Songs" and "the Miao Epic", is a unique form of the expression of Miao ancient songs, which is taken by reflecting ancient memories and current life experience in both question-and-answer Pan-Ge (work song) style, ancient and modern contrastive singing style. As the oldest oral language art form of the Miao ethnic, their epics carry the cultural memory of the ancient history of the Miao people. The cultural symbols contained in them have created a unique cultural world of the Miao ethnic. So far, the study on the translation of Hmong Oral Epics at home and abroad has lagged behind and been insufficient. Only eight related papers have been retrieved from academic journals online. Among them, Li Yanjuan (2014) discussed some translation skills from the perspective of original social ecology culture. Wu Yifang (2013) elaborated the cross-cultural interpretation of Miao oral classical literature (Wu, 2013).

Theoretically, most of the studies on the translation of Miao epics and other classics have stayed at a superficial theoretical discussion stage, which are all at a superficial level instead of a deep one. The theories used in those studies mainly include skopos theory, 
functionalist translation theory and so on. Although these theories reveal the rules of translation of national cultural epics in one way, they lack a comprehensive perspective. In addition, their research systems are not very sound, lacking the macro-theoretical perspective, the micro-analysis, and the provability of the system theory.

Translation studies are essentially a kind of cultural studies. Although the research on translation and communication of ethnic culture has experienced some innovations in methodology, interdisciplinary research and analysis methods should be adopted. As an integrated discipline of culturology and anthropology, the emerging cultural anthropology brings a new perspective to it. In recent years, cultural anthropology, a relatively young discipline, has been extensively used in other social sciences, including translatology. Their research objects are "human" and "culture", which have the commonality between methodologies. Cultural anthropology provides feasible approaches and strategies for the translation of Hmong Oral Epics, the most widely used of which is the Thick Translation theory. In terms of translation practice, the translation quality is also an important factor restricting the study on Hmong Oral Epics. However, the Hmong Oral Epics (MiaoChinese-English Version) translated by American Sinologist Mark Bender, Wu Yifang and Ge Rong has changed this situation. The book was published by Guizhou Ethnics Publishing House in September 2012. Once published, it caused a sensation in academic circles; especially the flexible use of thick translation strategies from the perspective of cultural anthropology makes it a successful model for the translation of ethnic classics. Starting from the thick translation theory, this paper will elaborate on the ethnography, and reveal the secret of the success of Mark Bender's translation of Hmong Oral Epics, which will promote more Chinese minority classics to be introduced to the world.

\section{LITERATURE REVIEW}

\section{Thick Translation from the Perspective of Cultural Anthropology and Translation of Classics}

Thick Translation: the Result from the Common Vision of Cultural Anthropology and Translation Studies

The thick translation is the result from the blending and learning of cultural anthropology and translation studies, which share certain similarities from the perspective of subject attributes, research methods and research objects. According to the American anthropologist Harris, cultural anthropology concentrates on the origin, development and evolution processes of human culture and he analyzes the characteristics of national cultures. Focusing on culture itself is precisely what institutes of translation studies value. Translation studies and cultural anthropology are humanities with culture and language as their research subjects. They both embody languages, cultures and symbols, and emphasize the process of intercultural communications. In terms of subject attributes, translation studies, as a media of language transformation, have a certain convergence with the cultural anthropology which studies human behavior culture.

In addition, the objects of translation studies and cultural anthropology study share a common perspective. Firstly, the text and the field are the two objects of common concern. Susan Bassnett, a British scholar, proposed the cultural turn in translation studies and the translation turn in cultural studies, whose essences are the shift of translation studies from language to culture (Allen, 2019). Furthermore, anthropology has also undergone a shift from field to text research. Evans-Pritchard described the central task of ethnographic research as "cultural translation". Thus, it can be seen that the paradigm shift of translation studies and cultural anthropology is essentially the same. Both of them introduce research into the culture of the target language and the culture of acceptance, and emphasize the 
impact of research practice process on acceptance context. Secondly, both translation studies and cultural anthropology focus on "the other". The former is to experience "the other" in the translated source text, while the latter is to contact "the other" in the field investigation. Thirdly, both translation studies and cultural anthropology emphasize on giving play to the subjectivity of translators or researchers. The translator is not only the subject of translation, but also an important participant in the construction of ethnic cultures (Nicholas, 2018). Cultural anthropology advocates the use of emic and pluralistic approach to write ethnography so as to minimize cultural bias. Meanwhile, it also holds that all truths are cultural constructions, and that they are relative and conditional. In terms of subjectivity, both have the same effect.

Furthermore, from the perspective of research methods, it is precisely due to the enlightenment of the interpretation and thick description of cultural anthropology that thick translation theory emerges. In the book "The Interpretation of Cultures", anthropologist Clifford Geertz points out that man is an animal suspended on the web of meanings woven by him, and culture is such a web. Therefore, anthropology is not an experimental science, but an interpretation of science, not an exploration of laws but of significance. The description of anthropology should not be "a pile of institutional material", but rather a thick description - "understanding others' understanding". Inspired by Geertz's thick description of cultural anthropology, Kwame Anthony Appiah, the professor of Princeton University and a Ghana - British-American philosopher, anthropologist and translator, published the paper entitled "Thick Translation" in 1993. In the paper he put forward the concept of "Thick Translation" or "Thick Contextualization" for the first time (Appiah, 1993), which set off a research upsurge of thick translation in the cross-cultural process.

According to the international academic search data, translation and anthropology studies have emerged since the end of the 1980s and have gradually increased in the new century. Most of them focus on the relationship between anthropology and translation, such as Borgatti \& Li (2009), Barker (2006), Bradby (2002), and Basu \& Simon (2008). Some Western scholars have explored the method of thick translation by applying the method of thick description in cultural anthropology to translation studies, such as Hermans (2003), Cheung (2007) and Sturge (2007). Thus, it can be seen that the relevant research has risen, but not yet mature. The representatives of thick translation studies in China include Duan Feng (2006) and Wang Hongyin (2010), et al. (Long, 2017). Such questions as "What is thick translation? What are the main points? Whether it is applicable to the translation of Hmong Oral Epics and other classics?" will be deeply discussed in the next part.

\section{The Theory of Thick Translation and the Feasibility of Its Application to English Translation of Classics}

To explore whether thick translation is applicable to the translation of Hmong Oral Epics and other classics, first of all, it is necessary to clarify the concept of thick translation and its theoretical development. As mentioned above, it was proposed by Kwame Anthony Appiah. He said, "But I had in mind a different notion of a literary translation; that, namely, of a translation that aims to be of use in literary teaching; and here it seems to me that such "academic" translation, translation that seeks with its annotations and its accompanying glosses to locate the text in a rich cultural and linguistic context, is eminently worth doing. I have called this "thick translation"; and I shall say in a moment why." (Appiah, 1993) Appiah's "Thick Translation" has three connotations, namely literary, academic and the way that commentaries and annotations are made between the margins of the translation and the line with attempts to put the translation into rich source 
languages and source cultural environment. It was first used in the English translation of African proverbs. The theory has exerted a great influence on the field of translation studies in the West. Lawrence Venuti included Apia's papers in his "Translation Studies Reader", which is a collection of papers focusing on outstanding Western translation studies in the 20th century and was first published by Routledge in the UK, the USA and Canada in 2000. In 2003, Theo Hermans, a British translation theorist, published a paper entitled "Cross-cultural Translation Studies as "Thick Translation", which took thick translation as an approach to study cross-cultural translation. It is believed that thick translation can not only avoid the tediousness of terms and the reduction in formats in translation studies, but also promote the production of more colorful and diversified vocabulary. According to Shuttleworth \& Cowie, although Appiah specially refers to the problems involved in translating African proverbs it is clear that the term may be applied to any target text (TT) which contains a large amount of explanatory material, whether in the form of footnotes, glossaries or an extended introduction. The purpose of providing such voluminous background information is to make the TT reader engender a deeper respect for the source culture and a greater appreciation for the way that people of other background shave thought and expressed themselves. These imply that "Thick Translation" has been recognized and used by translators abroad.

In the new century, the "Thick Translation" notion studies began to become popular after having been introduced into China. Most of them are of theoretical level, while a few involve guiding translation practice. Domestic translation theorists have different opinions on what thick translation is. However, The core of the concept is to add various annotations, comments, notes and long prefaces to the translated text, put the translated texts into rich cultural and linguistic environments and try to reconstruct the historical atmosphere when the source language text came into being, so as to facilitate the integration of meanings obscured by words with the intention of translators. Duan Feng (2006) argued that thick translation was a common method in translation practice, and its theory originated from the thick description theory of cultural anthropology and the theory of historical context of New Historicism. Sun Ningning (2010), combined with the thick description theory of Clifford Geertz who is an American cultural anthropologist, explored the relationship between translation and cultural anthropology, and pointed out that the essence of the thick translation from the perspective of cultural anthropology was translation and interpretation. By investigating the phenomenon of "thick translation" in the English version of the book "Xuncius" translated by American sinologist John Nobnock, Huang Lin (2013) analyzed the reasons behind this phenomenon and explored the positive significance of "Thick Translation" strategy, especially its great value to the study on translation of Chinese classics.

As unique Chinese linguistic and cultural phenomena were contained in ancient books, translating classics into English is not only a process from one language to another, but also a great leap from ancient to modern in time and from one country to another in space, which has brought lots of difficulties to the translation of classics, especially cultural translation ( $\mathrm{Yu}$ and $\mathrm{Wu}, 2018)$. In order to help target language readers understand this kind of leap, a "cultural network" generated in the original language text can be constructed in the target language, under which the target language readers can understand the original text more easily, so as to avoid misunderstandings and distortion of the original text caused by incorporating it into the thinking pattern and cultural presupposition of local culture due to language conversion. This method is suitable for translating classics with rich cultural information. However, there are few studies on the translation of Chinese minority classics. Likewise, only small amount of researchers combine thick translation 
with Hmong Oral epics in the existing literature. Wang Zhiguo's research with ethnographic translation method is one of a few research having a high reference value for this paper so far. Despite this, Few literature have been able to systematically and comprehensively examine this aspect. This study therefore will further analyze the realization and advantages of "thick translation" in Miao epic, aiming to provide reference for international communication and exchange of ethnic classics.

\section{RESEARCH METHODS}

\section{Thick Description}

The anthropological method of thick description has been repeatedly applied to the studies of cultural translation, and thus the notion of think translation came into being. The theory of thick translation has been discussed in the above part, it is also the major research method in this paper. Briefly, it is an approach to translation of associating the source text with its cultural environment through the addition of annotations, elaborations, commentaries and the like to the regular translation, to ensure that the background cultural features of the source text can be remained in the target text as much as possible. In this way, it enables the target readers to go back to the cultural context in which the source text was produced, and understand what the source text producer actually thought in his or her mind.

\section{RESULTS AND DISCUSSION}

\section{A Model of Thick Translation in Cultural Anthropology: Ethnographic Interpreta- tion of Hmong Oral Epics (Miao-Chinese-English Version)}

English Translation Course of Hmong Oral Epics

Hmong Oral Epics is a narrative poem of the Miao folk creation mythology. It has been spread in the Miao-populated area of Qingshui River in eastern Guizhou Province. According to the textual research of $\mathrm{Wu}$ Yiwen and Tan Dongping, it is no later than the Tang Dynasty (618-907) that the main part of Hmong Oral epic had been finalized, but was rarely known by people. The earliest records of Hmong Oral Epics are some epic chapters in "Floods", "Brothers' and Sisters' Marriage" and "Creating Heaven and Earth" recorded by British missionary Clark in cooperation with Hmong Pan Shoushan in 1896. After the founding of the People's Republic of China, Ma Xueliang and Jin Dan from Minzu University of China began to collect the Miao folk culture since the 1950s. The collection contains about 300,000 words which includes Miao ancient songs, love songs, wine songs, legends and witchcraft lyrics and has lasted for 30 years. In 1983, the Mandarin Chinese version of the Hmong Oral Epics jointly signed by Ma Xueliang and Jin Dan was officially published by the Chinese Folk Literature and Art Publishing House. A total of 7,500 copies were printed and sold out soon. Today, the book is out of print. Jin Dan is considered to be the first scholar to propose the Chinese translation of the Hmong Oral Epics. In addition, many ethnic folk literature workers carefully collected and found a lot of variants of the Hmong Oral Epics, which attracted the attention of domestic and foreign researchers. Miao Ancient Songs collated by Guizhou Provincial Folk Literature Group, edited by Tian Bing and published by Guizhou People's Publishing House is one of the better versions.

Ma Xueliang and Jin Dan's Hmong Oral Epics and other several editions of Miao Ancient Songs published at the same time are in both Miao-Chinese version and I.P.A. version. The English translation in the true sense came out in 2006. At Jin Dan's invitation, professor Mark Bender, a sinologist at Ohio University, translated and published Ma Xueliang and Jin Dan's Hmong Oral Epics into English, with the title of "Butterfly Mother: 
Miao (Hmong) Creation Epics from Guizhou, China". In 2012, Hmong Oral Epics, a trilingual edition of Miao, Chinese and English, was published by Guizhou Ethnics Publishing House. The book is a collection of 800,000 words of Hmong ancient epics and 66 color pictures related to epic culture collected from the 1950 s to 21 st century. After the publication of this book, positive reactions had been aroused in the epic circle at home and abroad. Some scholars pointed out in their book reviews that the reason why the book was "a landmark classic" in the history of the Miao culture is because that it not only fills the gap in the multilingual translation of Miao ancient classics, but also builds a bridge of cultural exchange for the Miao ancient songs which has been gradually becoming an international prestigious doctrine. In November 2012, the book translated by Mark Bender was regarded as "the classic text of transnational cooperation" at the International Summit on Epic Studies, and won the first prize for outstanding social science achievements in Guizhou Province.

The publication of this book is by no means accidental. Publishing Trilingual edition of Hmong Oral Epics is a dream of Ma Xueliang and Jin Dan. In an era when living traditions are on the verge of disappearance, this oral tradition of Miao language and their inheritors are about to leave the stage. This book will also become a rich heritage of the local Miao people in this era. In addition, although Miao ancient songs have been translated into Chinese before. $\mathrm{Wu}$ Yiwen did not find any original in Miao language when he studied and collated the achievements of other scholars. Therefore, if only Chinese translations are studied, ambiguities or even errors may arise due to inaccurate translations. Based on this, $\mathrm{Mr} \mathrm{Wu}$ Yiwen and his father collated the original texts of the Miao ancient songs and translated them into a Miao-Chinese version. Then at the initiative of Guizhou Ethnic Publishing House, Professor Mark Bender joined again, making the birth of the MiaoChinese-English version of Hmong Oral Epics inevitable. The translation of the book is the result from multilateral cooperation and collective wisdom. In addition to Mark Bender, there are others who made great contribution to the translation of this book, such as young American sinologists Ge Rong and Wu Yifang who is the sister of Wu Yiwen. Wu Yifang is the only translator in the project team who is a native speaker of Miao and is proficient in both Chinese and English. The Chinese translation of the book is written in sevencharacter verse and follows the principles of faithfulness, expressiveness and elegance, with 3000 Chinese and English annotations, so that the thick translation notion is fully reflected in the translation, thus facilitating readers of different languages to better understand the original text and promote the overseas dissemination of Hmong Oral Epics.

\section{Ethnographic Orientation of Hmong Oral Epics (Miao-Chinese-English Version)}

Ethnography is the core of cultural anthropology. It is a comprehensive and detailed analysis, description and study of specific ethnics and their culture based on field investigations. The object of ethnography study is "the other", thus observation and interviews are the most commonly used research methods, and the main research strategies include the emic perspective of local orientation and the etic perspective of researchers' orientation. Both ethnography and translation studies aim at "the other" and at the interpretation and interpretation of the other's language and culture. The convergence, integration and reference of ethnography and translation studies are of natural occurrence. Ethnographic theories and methods can be applied to translation studies.

Hmong Oral Epics, known as the "Classic" of Miao culture and the "Encyclopedia of Miao History and Culture", bears the cultural memory of the ancestors of the Miao ethnic. After the epic of Miao has gone through the stages of oral inheritance and text dissemination, it has formed a cross-dialect and cross-regional ethnic cultural community. 
At present, the epic of Miao is undergoing the transition from oral text to written text, with a tendency toward disseminating abroad through English translation, which is ethnographic representative. With translation as a bridge, Mark Bender and other translators bring this ethnic intangible cultural heritage to English readers, which is not only the process of cross-cultural translation but also a writing process of ethnography. In order to make a better cross-cultural interpretation and to enhance English readers' understanding of the Miao culture in the English version of Hmong Oral Epics, translators have conducted a lot of fieldwork. As has been mentioned, Mark Bender is a professor and $\mathrm{Ph} . \mathrm{D}$. of literature in the Department of East Asian Languages and Literatures, Ohio State University, USA. His mother tongue is English and his teaching and research interests include Chinese literature, folklore, performance studies, and the study of Chinese ethnic minority culture. He has contributed a lot to the spreading of Chinese national culture abroad. Dr Mark Bender is also one of the earliest American scholars to work and conduct academic research in China since the reform and opening up. In 1985, he began to translate Hmong Oral Epics into English. He made extensive fieldwork and consulted Jin Dan and other Chinese experts with an open mind to gain an in-depth understanding of the historical origin of the Miao people. Most valuable of all, as one of the researchers of performance theory in America, he combined the textual analysis of the Miao epics with the empirical study of field work to put forward the important academic proposition of "performance in creation". He put the authors, inheritors and receivers of Miao epics in a three-dimensional space for macro-comprehensive investigation and took into account the respective roles and positions of many factors in oral literature translation so as to preserve the cultural context of epic ethnography from multiple perspectives. Mark Bender believes that although the number of Miao epic singers has declined sharply since the 1980s, there are still singers active in many ceremonial activities. The epics may be reinterpreted, be moved forward in a new context, or kept in the life of the Miao people. Mark Bender applied the above ethnographic methods to his translation practice, which makes the English version of Hmong Oral Epics be regarded as a model of research-based ethnographic translation.

\section{Thick Translation of Hmong Oral Epics beyond and within the Translation}

Thick translation is the most typical feature of the translation of Hmong Oral Epics, which shows an obvious thick contextualization. It constructs a cognitive context by adding situational context, cultural context and linguistic context (Wang, 2019), so that it can effectively help overseas readers understand the translation and source culture. Compared with the traditional translation method of classics, the thick translation of Mark Bender's Hmong Oral Epics (Miao-Chinese-English version) is more clear and thorough (see Table 1 for details).

Table 1. Comparison between traditional translation method and thick translation

\begin{tabular}{|l|l|l|}
\hline $\begin{array}{l}\text { Thick type } \\
\text { version }\end{array}$ & Thick translation within the translation & $\begin{array}{l}\text { Thick translation beyond the } \\
\text { translation }\end{array}$ \\
\hline $\begin{array}{l}\text { Traditional } \\
\text { translation }\end{array}$ & Implicit annotations & $\begin{array}{l}\text { Preface, introduction, illustrations, } \\
\text { references }\end{array}$ \\
\hline $\begin{array}{l}\text { Mark Bender's } \\
\text { translation }\end{array}$ & $\begin{array}{l}\text { parenthetical annotations, post- } \\
\text { paragraph comments, endnotes }\end{array}$ & $\begin{array}{l}\text { Preface, introduction, guidance, } \\
\text { prelude, translation notes, } \\
\text { illustrations, original texts, } \\
\text { references }\end{array}$ \\
\hline
\end{tabular}

The thick translation beyond the translation includes congratulatory messages, prefaces, introductions, introductory remarks, postscripts, indexes, glossaries, illustrations, 
appendices, references, Back-Cover recommendations and other forms. Introductory remarks (introduction) often play an outlining role in translation, which helps guide readers to grasp the structure and layout of the original work as a whole and clarify the logical relationship between the chapters of the original work, thus deeply understanding the essence of the original work and the author's writing intention. Hmong Oral Epics is relatively unfamiliar to overseas readers. To this end, Wu Yiwen wrote a 27-page article as the preface entitled "Oral Texts and Hmong Sprit: A discussion of the History and Culture of the Hmong epics (as preface)", where he spared no effort to explain the context of the Hmong epics clearly. The second part is preface to the English translation of Mark Bender. Mark bender reviewed the origin and feelings of the translation. There is one detail worthy of mentioning, namely, the word "Hmong" in Hmong Oral Epics was originally translated into "Miao". However, considering that Miao people are widely distributed in the world, not only in the Southeast Asian countries, but also in Europe and America, many of them do not understand Chinese. As a result, the word "Hmong" is used to highlight the value of international dissemination of the translation. The Prelude in the third part contains an introduction to the Miao ethnic and Miao ancient songs in over 20,000 words that was written by Mark Bender. In addition, the English version of Hmong Oral Epics is translated in the form of long and short sentences in the traditional dialogue structure of the Miao ancient songs. Each group of epic poems is preceded by explanatory notes to guide readers. For example, the introduction to The Song of Gold and Silver introduced the concepts of creating heaven and earth, transporting gold and silver, creating the suns and moons, shooting the suns and moons. All of these are the great feats of the Miao ancestors' understanding of the formation of the universe and the creation of the heaven and earth. Furthermore, 66 color paintings related to epic culture vividly show the historical and cultural context of the epic. To a certain extent, the above has promoted readers' deep understanding of the source language culture.

The thick translation within the translation, as the name implies, refers to the thick translation in the body of the translated text, including the implicit annotations, parenthetical annotations, double-line small annotations, footnotes, post-paragraph comments, endnotes and other forms. The epic uses a larger space to provide over 3,000 annotations, such as explanatory notes, the interpretation of ancient words, the annotations of characters, the annotations on ancient and modern place names, annotations on plants and animals, the interpretation of important customs, sentence interpretation, paragraph interpretation, and the contrast between variations. For example, the commentary on gallnut in Creating Heaven and Earth is translated thickly by the translator as follows:

The Hmong language for this line is "Ghab nix pab nil nangl". It refers to various types of leaves, cogon grass roots, and gallnut of the Chinese gallnut (Rhus Chinensis) tree, known aspabin Hmong and wubeizi in Han; pricklycastoroiltree (Kalopanax), known as det bel tongd in Hmong; saw-tooth oak (Querus acutissima), known as detyelin Hmong, and cogon grass are bundled and hung over doorways of Hmonghomes to ward off negative spiritual forces. Chinese gallnut is regarded as a numinous tree that links the human world with that of the spirits. The tree is an essential component of virtually allrites honoring the spirits. Its wood is used to make blocks cast in divination rites. In offering such as to the spirit Ghab Hvib, the poles used to support streamers are also made of gallnut.

This paper draws on the experience of the thick description of cultural anthropology to the greatest extent. Translators can compensate for cultural gaps in the translation of classics into English in the form of annotations. Such annotations are ubiquitous, aiming to help readers understand and appreciate poetry readings, and deal with the analysis on cultural background differences, the compensation for the absence of cultural phenomena, 
the transformation of different cultural phenomena, and even the characteristics of poetic rhymes perfectly.

For the lack of cultural phenomena, in addition to free translation and annotations, the form of same compensation and endnote is adopted. The part of "Creating the Suns and Moons" described that after the twelve suns and twelve moons were created and they were named after the Twelve Earthly Branches which are the cultural phenomena shared by the Miao and Han nationalities. In Miao language, the Twelve Earthly Branches are called, hxud, yenx, mol, xenx, sail, ngux, mais, hxenb, yul, hxenk and hat, respectively. They are used to represent the order, corresponding to the Chinese characters zi, chou, yin, mao, chen, si, wu, wei, shen, you, xu and hai. The Chinese zodiac is no longer unfamiliar in the English-speaking countries. They are intuitive, easy to understand and to remember, vivid and interesting. Therefore, the translator has to translate the twelve earthly branches into the corresponding twelve zodiac animals, and add the English endnotes to explain the twelve earthly branches and twelve zodiac animals:

"The Earthly Branches (dizhi in Han) are part of an ancient Chinese system used to calculate time based on the twelve year orbit of the planet Jupiter. The various time units that make up a day are based on twelve animal names. Different cultures in East Asia use somewhat different animals. In the Hmong version used in epics, the twelve branches are represented by the rat, ox, tiger, hare, dragon, snake, horse, sheep, monkey, rooster, dog and pig”.

In this way, the translation corresponding to the annotations helps the reader to fully understand them.

\section{CONCLUSION}

As the oldest form of oral language art of the Hmong, Hmong Oral Epics is also the first translation of the creation epic named after the national identity in China. Through the comprehensive application of various thick translation strategies, translators better explained the idea of "putting the translated text in the deep linguistic and cultural context of the source language" proposed by thick translation. Meanwhile, the translators' tolerance of and respect for the original and other cultures are also highlighted. Admittedly, thick translation makes the translation too cumbersome and less readable due to a large number of annotations and long prefaces. However, such defects cannot belittle virtues. For the translation of national classics, thick translation is indeed an effective translation strategy, which is conducive to the dissemination of Chinese classics abroad. Furthermore, the anthropological ethnographic interpretation method adopted by the translation leads these obscure national classics to the overseas ordinary readers from its academic palace. Moreover, the interdisciplinary and cross-border translator cooperation model, unique translation style, and holographic cultural interpretation mode created by its translation provide a new paradigm for the English translation of the classics of various nationalities throughout the world.

\section{AKNOWLEGEMENTS}

This work was a project supported by Hunan Provincial Social Science Fund "Research on Translation of Miao Culture Classics in Western Hunan Area under the Perspective of Cultural Anthropology"(Grant No. 18ZDB005), also by Scientific Research Fund of Hunan Provincial Education Department "A study on the English Translation of Hmong Epics from the Perspective of Ethnographic Thick Translation" (Grant No. 19B130) 


\section{REFERENCES}

Allen, J. R. (2019). The Babel Fallacy: When Translation Does Not Matter. Cultural Critique, 102(1), 117. doi:10.5749/culturalcritique.102.2019.0117

Appiah, K. A. (1993). Thick Translation. Callaloo, 16(4), 808-819.

Baker, M. (2006). Contextualization in translator- and interpreter-mediated events. Journal of Pragmatics, 38(3), 321-337.

Hermans, T. (2003). Cross-cultural translation studies as thick translation. Bulletin of the School of Oriental and African Studies, 66, 380-389.

Jixing, L. (2017). An Anthropological Perspective of Ethnography and Translation Studies. English Studies, 5(1), 97-104.

Jose, N. (2018). The Dao of translation: an East-West dialogue. Translation Studies, 11(1), 105-107. doi:10.1080/14781700.2017.1289862

Wang, L. (2019). Function and Application of Context in English-American Literary Translation. Argos, 36.

Yifang, W. (2013). The Cross - cultural Translation of Miao People's Oral Literary Classics: On the Trilingual Translation of "The Epic of the Miao People". Journal of Guizhou Minzu university (Philosophy and Social Science), 32(4), 6-12.

$\mathrm{Yu}, \mathrm{H} .$, \& Wu, C. (2018). Attitude as mediation: Peritextual commentary in the translation of the Platform Sutra. Text \& Talk, 38(5), 633-654. doi:10.1515/text-2018-0017

Zhiguo, W. (2017). Ethnographic Interpretation on the Translation of Folklore Items in Hmong Oral Epics Folklore Studies. Folklore Studies(01), 116-121+159-160. doi:10.13370/j.cnki.fs.2017.01.015 